\title{
TRABALHO, CRISE E POLÍTICAS ASSISTENCIAIS: Análise dos impactos do programa bolsa família no índice de desenvolvimento humano brasileiro // Jailton Macena de Araujo $^{1}$
}

\section{Palavras-chave}

políticas assistenciais / programa bolsa família / índice de desenvolvimento humano / trabalho / eficiência socioeconômica

HIIIIIIIIIIIIIIIIIIIIIIIIIIIIIIII

\section{Sumário}

\section{Introdução}

2 Repercussão socioeconômica do Programa Bolsa Família

3 Eficiência dos programas sociais: avaliação empírica dos valores de repasse do Programa Bolsa Família em face das variáveis do IDH.

3.1 Repercussões sociais do Programa Bolsa Família: impactos do PBF nas variáveis do IDH e nos direitos sociais à educação e à saúde.

3.2 Repercussões econômicas do Programa Bolsa Família: impactos do PBF na variável renda do IDH e no acesso ao trabalho.

4 Programa Bolsa Família $x$ trabalho: repercussão socioeconômica das ações assistenciais na demanda por trabalho

5 Conclusão

6 Referências

\section{Resumo}

No Brasil, programas assistenciais como o Programa Bolsa Família (PBF) funcionam como instrumento de acesso aos direitos sociais que promovem uma meIhoria nas variáveis que compõem o Índice de Desenvolvimento Humano (IDH). Nesse sentido, o presente trabalho busca responder as seguintes questões: é possível depreender dos dados do IDH brasileiro a eficiência do PBF? E de que maneira a resposta a essa pergunta pode ajudar a observar a relação entre políticas assistenciais e trabalho? Pretende-se demonstrar os indícios positivos da reestruturação da assistência social, no sentido do desenvolvimento e o seu impacto no IDH brasileiro. Para tanto, utilizar-se-á dos dados empíricos no intuito de permitir a avaliação prático-teórica da correlação entre o direito à assistência social, implementado pelo Bolsa Família, e o índice de desenvolvimento humano. Desse modo, a análise empírica da repercussão socioeconômica das ações assistências do Programa Bolsa Família acabam por influenciar a demanda por trabalho, gerando uma necessidade ampla de que o Estado promova ações de enfrentamento à pobreza, especialmente no contexto hodierno de crise.
1 Doutor em Ciências Jurídicas, área de concentração Direitos Humanos e Desenvolvimento, pela Universidade Federal da Paraíba (2016), mestre em Ciências Jurídicas, área de concentração em Direito Econômico, pela Universidade Federal da Paraíba (2011) e graduado em Direito pela Universidade Federal de Campina Grande (2007). Atualmente é professor do Curso de Direito, vinculado ao Departamento de Direito Processual e Prática Jurídica (DDPPJ), do Centro de Ciências Jurídicas (CCJ) da Universidade Federal da Paraíba. 


\section{WORK, CRISIS AND ASSISTANCE POLICIES: Analysis of Bolsa}

\section{Família program impacts on Brazilian index human development //}

\section{Jailton Macena de Araujo}

\section{Keywords}

assistance policies / bolsa família program / human

development index / work / socioeconomic efficiency

\begin{abstract}
In Brazil, welfare programs such as "Bolsa Família" Program (PBF) function as an instrument of access to social rights that promote an improvement in the variables that compose the Human Development Index (HDI). In this sense, the present work seeks to answer the following questions: is it possible to deduce from the data of the Brazilian HDI the actual "PBF"? In which way the answer could help observe the relationship between welfare policies and work? We aim to demonstrate the positive signs of restructuring social assistance, in the sense of development and its HDI impact in Brazil. Empirical data was used to allow a practical-theoretical evaluation of the correlation between the right to social assistance, implemented by Bolsa Família, and the human development index. Thus, an empirical analysis of the socioeconomic repercussion of the assistance actions of the Bolsa Família Program end up influencing the demand for work, generating a broad need for the State to promote actions to combat poverty, especially in the current context of crisis.
\end{abstract}




\section{Introdução}

As ações da assistência social denotam um modo de agir do Estado, cujas funções são pautadas num determinado fim, que é o desenvolvimento, nos termos estabelecidos pelo texto constitucional (art. 3, II, CF/1988). É por meio da racionalidade de base constitucional, estabelecida no plano teórico pelo planejamento, posto em prática através das políticas públicas, que as repercussões práticas dessas ações sociais, voltadas para o desenvolvimento, são sentidas pelos cidadãos.

A implementação das ações de desenvolvimento pelo Estado se dá pelo exercício de seus agentes na realização de suas funções, órgãos e estruturas, de cunho constitucional, por meio das quais se promove uma alteração social, dada a necessidade de atuação positiva estatal no sentido de conformar a realidade de vulnerabilidade social que atinge a imensa maioria dos cidadãos brasileiros pobres aos objetivos constitucionais. É nessa perspectiva que se pode afirmar que analisar o desenvolvimento por meio de políticas públicas apenas faz sentido se o desenvolvimento nacional for considerado a principal política pública, conformando e harmonizando todas as demais políticas do Estado.

A elaboração e implementação das políticas públicas deve ser parte da longa manus estatal definida na Constituição, no interior da qual os valores e interesses sociais são estabelecidos. É nesse sentido que se afirma que as políticas públicas brasileiras de cunho social têm fundamento constitucional direto, uma vez que a força normativa da constituição acaba por determinar, de modo claro, quais ações devem ser executadas pelas autoridades legislativas, judiciais e administrativas.

Nesse horizonte, lança-se a questão: é possível afirmar a eficiência do Programa Bolsa Família (PBF) em face dos dados apresentados pelo Índice de Desenvolvimento Humano (IDH) brasileiro? Como essa resposta contribui para pensar a possível relação entre as políticas assistenciais e a realização do valor trabalho como instrumento de promoção do desenvolvimento? Para que seja possível responder a essas questões, pretende-se avaliar a implementação da política pública desenvolvida no âmbito do Programa Bolsa Família a partir da análise de dados de base empírica.
Ao longo do texto, os dados são apresentados no sentido de demonstrar indícios da reestruturação da assistência social, com fulcro no valor social do trabalho, os quais permitem visualizar os seus impactos positivos no IDH brasileiro. Utilizar-se-á na argumentação os dados empíricos, da realidade brasileira, no que se refere a implementação do principal programa assistencial brasileiro, no intuito de permitir a avaliação prático-teórica da correlação entre o direito à assistência social, implementado pelo Bolsa Família e a sua interconexão com o valor desenvolvimento, na medida em que são implementadas as ações assistenciais.

O trabalho está divido em seções, nas quais se pretende apresentar a repercussão socioeconômica do Programa Bolsa Família, tratando, em particular, da eficiência dos programas sociais, a partir de uma avaliação fundada em dados empíricos. Na primeira seção, correlacionam-se os valores de repasse do Programa Bolsa Família e as variáveis do IDH, pelo que se pretende demonstrar as repercussões socioeconômicas no exercício dos direitos à educação e à saúde. $\mathrm{Na}$ segunda seção, demonstram-se as repercussões econômicas do PBF, além dos impactos na variável "renda" do IDH, bem como no acesso ao trabalho. $\mathrm{Na}$ última seção, em face da articulação do Programa Bolsa Família e do trabalho, enquanto valor, a análise empírica da repercussão socioeconômica das ações assistenciais acaba por reconhecer que a demanda por trabalho gera, para o Estado, ampla necessidade de promoção de ações de enfrentamento da pobreza, especialmente no contexto hodierno de crise.

\section{Repercussão socioeconômica do Programa Bolsa Familia}

Como se pode depreender da realidade atual, são muitos os problemas socioeconômicos que afligem o Estado brasileiro (relacionados à situação de precariedade econômica e à condição de pobreza que atinge milhares de brasileiros), os quais são agravados por uma crise social, econômica e política, de proporções inéditas nos últimos 15 anos.

Pode-se afirmar que o contexto socioeconômico atual é resultado de uma crise do capitalismo. 0 capital especulativo interfere sobremaneira na condução 
dos processos econômicos; e a retração do mercado global descortina o retrocesso econômico no decorrer do qual se configura o retrocesso social. Consequência disto é a deflagração de limitações e impedimento de acesso a bens sociais².

Na reflexão sobre o tema, sói ocorrer construções teóricas de diagnósticos açodadamente engendrados, no sentido de afirmar que direitos sociais são vilões hábeis a comprometer a pujança no mercado. Demais disso, o sempre decantado agravamento do cenário em razão de crises política e de representatividade, sem precedentes na história da democracia brasileira recente militam a favor das saídas legislativas tendentes a "desconstitucionalização" de direitos sociais, como o recente Novo Regime Fiscal aprovado.

O incremento de mazelas sociais, decorrentes da crise, embora tenham sido agravadas nos últimos anos, assentam na racionalidade econômica sua origem histórica. Referido critério de racionalidade dita rumos ao Estado e as escolhas dos agentes na condução dos processos econômicos, sociais e políticos. Nessa medida, a elaboração de uma estratégia de inserção social, instrumentalizada pelo Programa Bolsa Família (PBF), tem sido capaz de promover uma alteração considerável nos índices e indicadores de bem-estar.

Os resultados obtidos com o PBF possibilitaram o reconhecimento dos efeitos positivos de suas ações no combate à exclusão socioeconômica, ainda que sua implementação se verifique em contraposição à racionalidade dominante. Isso porque, desde o ano de 2003, com a implementação do PBF, o aporte de recursos na economia tem sido realizado de modo a promover a inserção e o desenvolvimento das pessoas em condição de pobreza e extrema pobreza.

O Bolsa Família funciona a partir da transferência de renda condicionada aos seus beneficiários, pessoas pobres, cuja renda familiar per capita não ultrapassa um quarto do salário mínimo. O centro das preocu-

\footnotetext{
2 Bens sociais são os elementos concretos que constituem o exercício e a fruição dos direitos sociais (previsões legais do acesso a esses mesmos bens). Por exemplo. 0 direito (social) à educação, reflete-se no acesso às escolas de qualidade (bem social), o direito social à alimentação reflete-se no acesso à comida nutritiva, saudável, fresca (bem social) etc.
}

pações na implementação das ações assistenciais do Bolsa Família é a realização das metas de equidade e de acesso a bens mínimos, o que demonstra a ligação ao valor solidariedade de base constitucional.

No Brasil, são altos os índices de incidência da pobreza e da desigualdade. Segundo dados da Pesquisa Nacional por Amostra de Domicílios (PNAD) de 2013, embora tenha havido uma redução do número de pobres e extremamente pobres, cerca de 15,7 milhões de pessoas ainda vivem em condições de miserabilidade. Para que se possa alcançar uma situação de desenvolvimento, como se objetiva no texto constitucional, é essencial que haja a promoção das condições favoráveis à sua realização, em relação a esses sujeitos.

Nesta perspectiva, o Bolsa Família tem promovido a integração dos mais pobres à economia, garantindo a ampliação das ações voltadas à distribuição de renda e à garantia de oportunidades sociais. Ainda de acordo com a PNAD (2013), o Bolsa Família resgatou, até 2012, cerca de $80 \%$ das pessoas em condição de extrema pobreza, tendo sido responsável pelo atingimento e superação de uma das metas dos Objetivos de Desenvolvimento do Milênio (ODM), consubstanciadas na redução, pela metade, do número de pessoas vivendo em extrema pobreza até 2015 (em 2002 eram 41 milhões de pobres, em 2012 esse número diminuiu para 15,7 milhões).

Nesse sentido, veja-se a Tabela 1, com a evolução dos índices que compõem o Índice de Desenvolvimento Humano ${ }^{3}$ brasileiro, nas suas variáveis expectativa de

30 Índice de Desenvolvimento Humano (IDH) "surgiu em 1990 como contraponto à utilização do Produto Interno Bruto (PIB) per capita como único parâmetro para mensurar o desenvolvimento dos Estados. [O IDH foi] criado por Mahbub ul Haq, com a colaboração do economista indiano Amartya Sen, no intuito de se transformar numa medida geral e sintética do desenvolvimento humano. Embora não abranja todos os aspectos do desenvolvimento, o IDH representa uma forma objetiva de avaliar as condições de vida das pessoas, nas mais diversas regiões do globo, não representando, conquanto não seja o seu objetivo, a 'felicidade' das pessoas, nem muito menos o 'melhor lugar no mundo para se viver'. O índice considera três aspectos para o seu cálculo: a renda, mensurada pelo PIB per capita (corrigido pelo poder de compra de cada Estado); a longevidade, calculada a partir da expectativa de vida ao nascer e dos níveis de saúde pública; e, a educação, sendo consideradas as taxas de analfabetismo e de matrículas efetuadas em todos os níveis de ensino. Todos os aspectos têm a mesma valoração no cálculo do índice que oscila entre zero e um. Quanto maior o índice, melhor a qualidade de vida da população do local analisado (QUIRINO, 2009, p. 67)”. 
vida no nascimento, expectativa de anos de escolaridade e média de anos de escolaridade e o Produto Interno Bruto (PIB) per capita:

Tabela 1: Evolução dos elementos que compõem o IDH no Brasil

\begin{tabular}{|l|l|l|l|l|l|}
\hline Ano & $\begin{array}{l}\text { Expectati- } \\
\text { va de vida } \\
\text { no nasci- } \\
\text { mento }\end{array}$ & $\begin{array}{l}\text { Expecta- } \\
\text { tiva de } \\
\text { anos de } \\
\text { escolari- } \\
\text { dade }\end{array}$ & $\begin{array}{l}\text { Média } \\
\text { de anos } \\
\text { de } \\
\text { escolari- } \\
\text { dade }\end{array}$ & $\begin{array}{l}\text { PIB per } \\
\text { capita } \\
\text { anual } \\
\text { (US\$) }\end{array}$ & $\begin{array}{l}\text { Valor } \\
\text { do } \\
\text { IDH }\end{array}$ \\
\hline 1980 & 62,7 & 9,9 & 2,6 & 9.154 & 0,545 \\
\hline 1985 & 64,5 & 11,1 & 3,2 & 8.409 & 0,575 \\
\hline 1990 & 66,5 & 12,2 & 3,8 & 9.740 & 0,612 \\
\hline 1995 & 68,5 & 13,3 & 4,6 & 10.602 & 0,650 \\
\hline 2000 & 70,3 & 14,3 & 5,6 & 10.722 & 0,682 \\
\hline 2005 & 71,7 & 14,2 & 6,6 & 11.517 & 0,705 \\
\hline 2010 & 73,1 & 15,2 & 7,2 & 13.794 & 0,739 \\
\hline 2011 & 73,4 & 15,2 & 7,2 & 14.031 & 0,740 \\
\hline 2012 & 73,7 & 15,2 & 7,2 & 14.081 & 0,742 \\
\hline 2013 & 73,9 & 15,2 & 7,6 & 14.275 & 0,744 \\
\hline 2014 & 74,5 & 15,2 & 7,7 & 15.175 & 0,755 \\
\hline 2015 & 74,7 & 15,2 & 7,8 & 14,145 & 0,754 \\
\hline
\end{tabular}

Fonte dos dados: PNUD, 2017). Elaboração do autor.

Os dados apresentados demonstram a relevância dos programas assistenciais enquanto instrumento de promoção do desenvolvimento humano, mais especificamente a partir dos anos 2000 (saltando de 0,682 para 0,739 em 2010).

Embora, não se possa ignorar a tendência de elevação do IDH, desde antes da criação do Bolsa Família, não se pode olvidar que as informações que determinam a parametrização numérica do IDH não se referem a um elemento quantitativo, exclusivamente. Ao contrário, o índice reflete, numericamente, as melhorias qualitativas que se expressam em alterações substanciais na vida das pessoas, especialmente, pelo fomento ao acesso à educação e saúde, que enfeixados demonstram a relevância do programa na evolução do IDH brasileiro (o que é expressamente mencionados nos relatórios da ONU ao longo dos anos).
Dado o notável espectro de abrangência do PBF, visualizável no alcance social que apresenta, a efetiva melhoria no IDH, na sua acepção qualitativa, relativa principalmente ao acesso aos bens sociais educação e saúde, ocorreu, de forma mais acentuada nos primeiros anos de sua implementação. No período inicial, entre o início dos anos 2000 e o ano de 2010, o avanço dos números que compõem o índice foi mais expressivo.

Já a partir do início da década de 2010, observa-se uma tendência à estagnação do IDH, embora, particularmente a partir de 2014, tenha havido, de forma menos acelerada uma elevação do índice. De toda forma, deve-se considerar que o Bolsa Família promoveu, desde 2003, a retirada de milhares de pessoas da condição de pobreza, influenciando positivamente no incremento do IDH brasileiro, a um custo econômico relativamente baixo para os cofres públicos.

O Programa Bolsa Família é objeto da dispensa, no ano de 2015, de 0,5\% (meio por cento) do Produto Interno Bruto Nacional (PIB). Conforme demonstrado na Tabela 2, a variação do gasto público com o programa, desde 2010, foi entre 0,3 e 0,5 pontos percentuais em face do valor total do PIB brasileiro:

Tabela 2: Panorama PBF e IDH: 2010-2015

\begin{tabular}{|l|l|l|l|l|l|}
\hline Ano & Famílias & Valores & $\%$ PIB & IDH & $\begin{array}{l}\text { Valor } \\
\text { médio } \\
\text { dos } \\
\text { benefí- } \\
\text { cios }\end{array}$ \\
\hline 2010 & $\begin{array}{l}12,8 \\
\text { milhões }\end{array}$ & $\begin{array}{l}15,38 \\
\text { bilhões }\end{array}$ & $0,3 \%$ & 0,739 & $\mathrm{R} \$ 94$ \\
\hline 2011 & $\begin{array}{l}13,4 \\
\text { milhões }\end{array}$ & $\begin{array}{l}17,37 \\
\text { bilhões }\end{array}$ & $0,3 \%$ & 0,740 & $\mathrm{R} \$ 119$ \\
\hline 2012 & $\begin{array}{l}13,9 \\
\text { milhões }\end{array}$ & $\begin{array}{l}20,07 \\
\text { bilhões }\end{array}$ & $0,3 \%$ & 0,742 & $\mathrm{R} \$ 145$ \\
\hline 2013 & $\begin{array}{l}14,1 \\
\text { milhões }\end{array}$ & $\begin{array}{l}24,6 \\
\text { bilhões }\end{array}$ & $0,4 \%$ & 0,744 & $\mathrm{R} \$ 150$ \\
\hline 2015 & $\begin{array}{l}14,1 \\
\text { milhões }\end{array}$ & $\begin{array}{l}24,7 \\
\text { bilhões }\end{array}$ & $0,4 \%$ & 0,755 & $\mathrm{R} \$ 167$ \\
\hline lhões & $\begin{array}{l}27,1 \text { bi- } \\
\text { Ihões }\end{array}$ & $0,5 \%$ & 0,754 & $\mathrm{R} \$ 164^{52}$ \\
\hline
\end{tabular}

Fonte: Elaboração do autor; MDS, 2015; PNUD, 2014. 


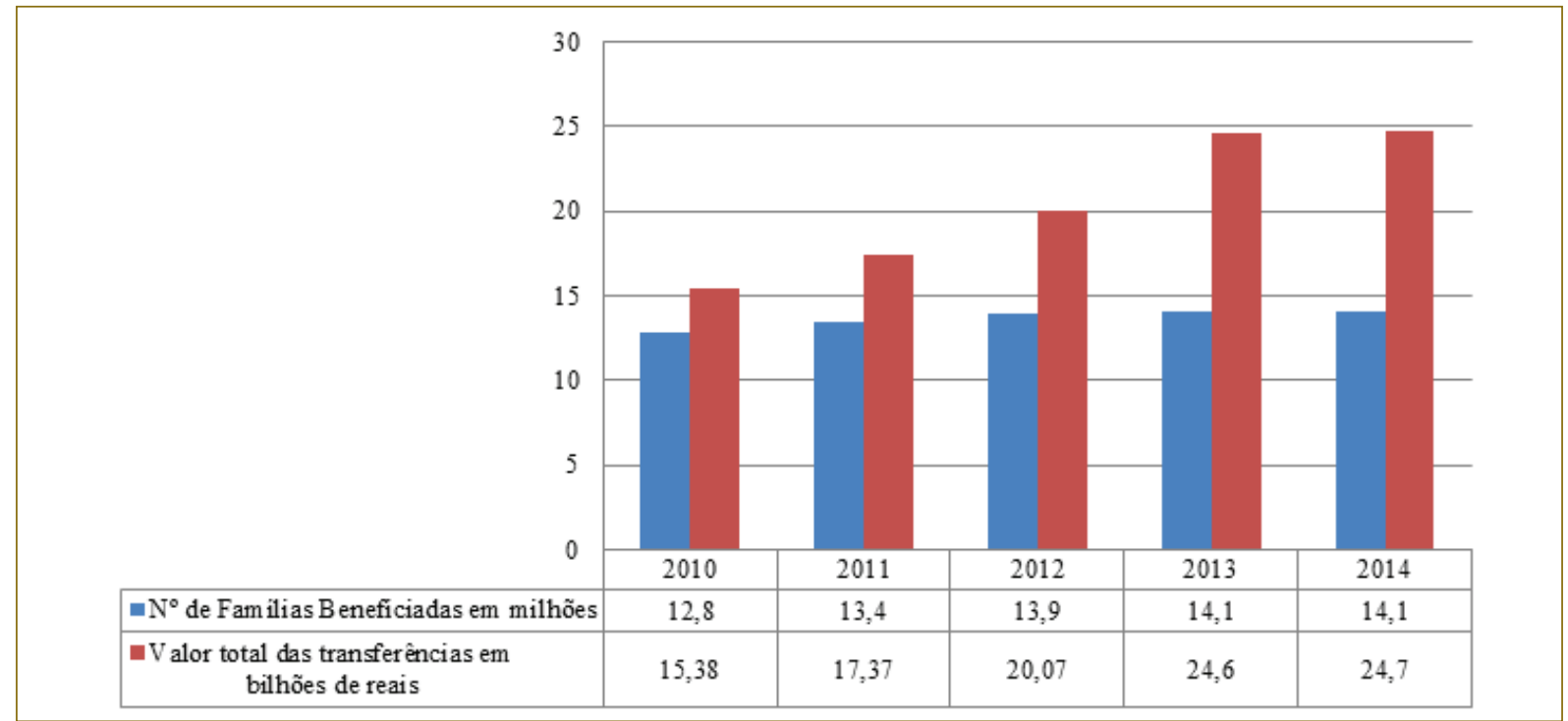

Relação número de famílias x valores transferidos - PBF (Elaboração do autor; MDS, 2014)

Embora o IDH brasileiro tenha passando apenas de 0,739, em 2010, para 0,744, em 2013, as condições sociais das pessoas vulneráveis socioeconomicamente têm melhorado consideravelmente, desde o início da implementação do Programa Bolsa Família, desde o ano de 2003. A partir de 2010, houve incremento considerável nos repasses relativos ao Bolsa Família, os quais mesmo com valores médios baixos, em torno dos R\$ 176,00 (em 2017), tem contribuído para o acesso dos seus beneficiários aos bens sociais capazes de promover o desenvolvimento.

Com base nos dados da última PNAD (IPEA, 2013), por força da qual foi realizada uma projeção socioeconômica acerca das repercussões decorrentes de uma possível inexistência do PBF, verificar-se-ia, nessa situação hipotética, um incremento percentual da população com renda mensal inferior a $\mathrm{R} \$ 70,00$ (setenta reais): os atuais 3,6\% (três inteiros e seis décimos por cento) saltariam para 4,9\% (quatro inteiros e nove décimos por cento).

4 Até outubro de 2015, o valor destinado ao Bolsa Família foi de R\$ 23.132.229.726,00 (BRASIL, 2015a). Segundo informações do MDS, o aumento dos repasses do programa serão consolidados até o final do ano de 2015, respeitando-se o cronograma de repasses dos recursos do Governo Federal (BRASIL, 2015b).

5 As informações relativas ao número de famílias, percentual do PIB e valor médio do benefício devem ser considerados tendo em conta que as informações referem-se até o mês de outubro de 2015.
Além do mais, a se considerar o elevado potencial de inserção social do PBF, vê-se que o programa agrega economicamente cerca de 5 vezes mais pessoas que o número efetivo de famílias beneficiadas diretamente. Há que se considerar que a ideia de inserção social deve ser avaliada na perspectiva de acesso aos bens sociais, especialmente, educação, saúde e renda, deste modo, avaliando-se o arco temporal de existência do Bolsa Família, e os números apresentados, quanto à evolução do IDH, há clara demonstração de melhoria nas condições de vida da população brasileira.

Os dados são representados no Gráfico 1, que demonstra a relação entre o número de famílias beneficiadas e o valor total das transferências realizadas.

Principalmente nas regiões mais pobres do Estado brasileiro, o Programa Bolsa Família tem atingido resultados extremamente exitosos. Suas ações têm propiciado renda mínima com vistas à superação da fome e ao alívio imediato da pobreza, atingindo cerca de 14 milhões de famílias - o que corresponde a quase $100 \%$ (cem por cento) das famílias que têm renda mensal per capita de até 154 reais. Esses valores representam, em termos de ramificação, o benefício, direto ou indireto, de cerca de 50 milhões de pessoas que compõem os núcleos familiares dos assistidos. 


\section{3}

\section{Eficiência dos programas sociais: avaliação empírica dos valores de repasse do Programa Bolsa Família em face das variáveis do IDH}

Os indicadores sobre o financiamento do Programa Bolsa Família demonstram a relevância dos gastos para a avaliação da eficiência da política pública assistencial. Isso porque, conforme Stone (2002), a eficiência não está ligada simplesmente à acepção comum do termo como sinônimo de algo que produz resultados positivos, mas ao sentido de que o emprego dos recursos econômicos deve promover o máximo de benefícios sociais aos cidadãos.

A eficiência das políticas públicas está relacionada, portanto, à correta e adequada utilização dos recursos públicos, razão pela qual se obriga o agente público a uma atuação que produza resultados favoráveis para a concretização dos objetivos do Estado, como dever jurídico da boa administração para a satisfação das necessidades de interesse público (COUTINHO, 2003, p. 104-106).

Fagnani (2009, p. 121-123) observa que há três indicadores sobre o financiamento e o gasto em políticas sociais que devem ser considerados na avaliação da política pública: (1) a direção do gasto social; (2) a magnitude do gasto social; e, (3) a natureza das fontes de financiamento. É nesse sentido que se pretende avaliar a ideia de eficiência socioeconômica representada pelas ações do Bolsa Família, em cotejo com as variáveis componentes do IDH.

Apesar do claro efeito, aparentemente temporário e assistencial da distribuição dos benefícios pecuniários, o principal objetivo do programa é o enfrentamento da pobreza, atuando em duas frentes: (1) no curto prazo, com o alívio imediato da pobreza por meio das transferências de renda; (2) em longo prazo, com a superação da condição de vulnerabilidade, viabilizada pelo exercício dos direitos sociais básicos nas áreas de educação e saúde, quando cumpridas as condicionalidades do programa.

A propósito dessa análise sobre as condicionalidades, o valor em dinheiro recebido pelos beneficiários do Bolsa Família como meio para "[...] sustentar um núcleo familiar em condições extremamente difí- ceis (REGO; PINZANI, 2014, p. 16)" não corresponde à única entrega do programa: as condicionalidades também são contraprestações que fundamentam a corresponsabilização do Estado e da sociedade, principalmente dos seus beneficiários, no sentido da consecução do desenvolvimento.

Institucionalmente, a exigência do cumprimento das condicionalidades desempenha verdadeiro papel de articulador social, pois contribui para o acesso e eficácia dos direitos sociais, reforçando assim o caráter universal das ações assistenciais, tantas vezes negligenciado por força de razões econômicas, tendentes a mitigar os titulares de seu exercício pleno. 0 acesso a esses bens sociais, em última análise, contribui para que as famílias consigam romper o ciclo da pobreza entre gerações, permitindo o acesso a direitos antes inacessíveis.

3.1 Repercussões sociais do Programa Bolsa Família: impactos do PBF nas variáveis do IDH e nos direitos sociais à educação e à saúde

Três fatores compõem o cálculo do IDH, renda nacional bruta per capita, acesso à educação e longevidade. Os dois últimos estão diretamente relacionados ao cumprimento das condicionalidades.

A partir das informações apresentadas no Gráfico 2, pode-se visualizar a evolução, especialmente a partir dos anos 2000, dos fatores que compõem o Índice de Desenvolvimento Humano, com o incremento considerável da média de anos de escolaridade do brasileiro.

A possibilidade de acesso à educação por crianças e adolescentes das famílias beneficiárias, viabilizada pelo $\mathrm{PBF}$, é fator decisivo nesse aumento, ocorrido especialmente a partir do ano 2005, após a consolidação da política assistencial.

Em vista disso, o PBF acaba por garantir mais do que o aumento da expectativa de escolaridade a crianças e adolescentes das famílias beneficiadas. Como demonstra o gráfico, o aclive na linha que afere a média real de anos de escolaridade da população brasileira revela que, entre 2000 e 2013, passou de 5,6 anos para 7,6 anos. Segundo dados do MDS, em relação ao cumprimento da condicionalidade "educação", o 
Gráfico 2: Evolução do fator educação no IDH

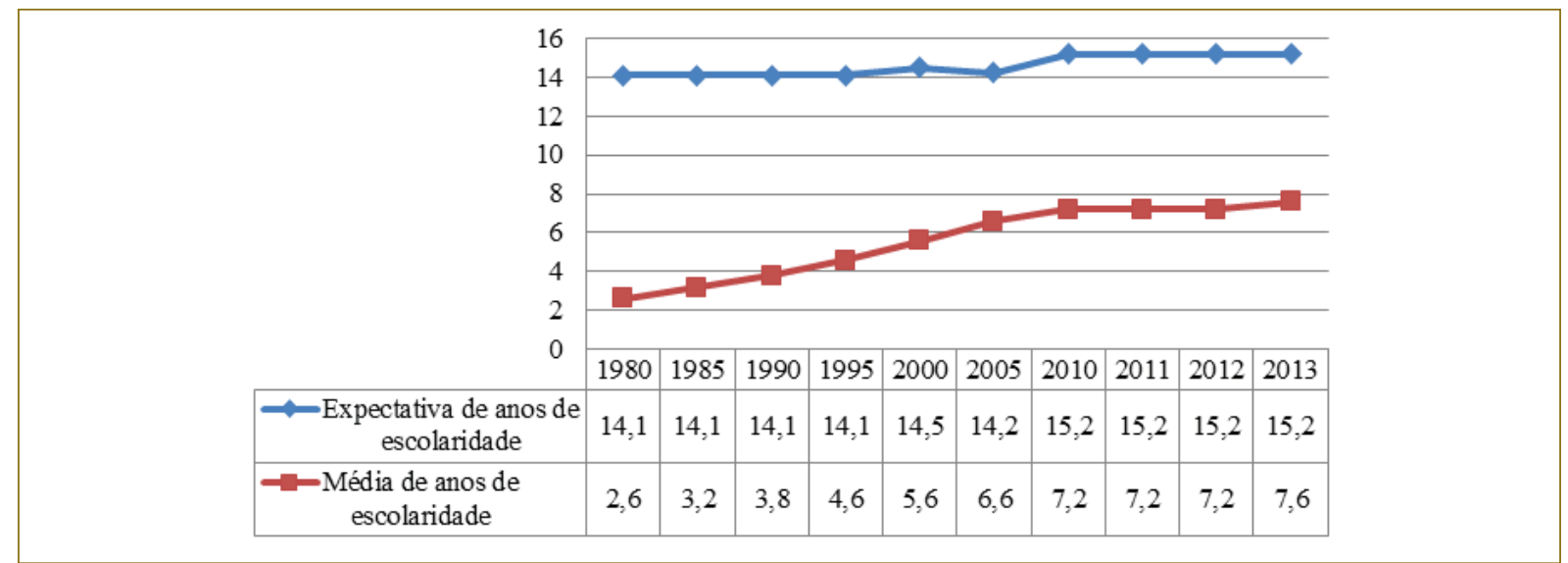

Fonte: Elaboração do autor; IPEA, 2014.

Brasil apresenta cerca de 17 milhões de alunos pertencentes a famílias beneficiárias do Bolsa Família matriculados na escola. ${ }^{6}$

Fica claro que embora haja evolução nos índices que compõem o IDH, o direito à educação e os instrumentos para a sua efetividade ainda podem ser melhorados, reduzindo o impacto negativo das deficiências educacionais no desenvolvimento e na emancipação das pessoas pobres. Embora o acesso à educação tenha se tornado quase universal, independendo da condição socioeconômica do aluno ou de sua família, o grande desafio que persiste é a qualidade do serviço prestado à população pobre.

A educação brasileira enfrenta problemas sérios de infraestrutura, principalmente nas localidades mais afastadas dos grandes centros, além de reproduzir deficiências no treinamento e formação dos professores, remunerando-os mal. O enfrentamento das desigualdades sociais passa por um aparelhamento dos serviços de educação, capaz de ampliar as possibilidades reais, não apenas de acesso, mas também de educação de qualidade, voltada para a capacitação laboral.

A exigência do cumprimento das condicionalidades relacionadas à educação fortalece a disseminação

6 Desse total, mais de 14,7 milhões tiveram suas informações cadastradas relativas à frequência escolar no período junho/julho de 2015, o que representa cerca de $87 \%$ daquele total. Desses, 14,1 milhões de alunos $(95,7 \%)$ cumpriram a condicionalidade educação, frequentando as aulas (BRASIL, 2015c). da ética do cuidado, convertendo-se em melhoria nas condições de saúde. Especialmente em decorrência do acesso e do atendimento das famílias mais pobres, houve também incremento positivo na variável longevidade do IDH. Como se pode depreender do Gráfico 3, houve, para os brasileiros, uma nítida ampliação da expectativa de vida ao nascer:

Nos últimos 30 anos, desde a década de 1980, a expectativa de vida do brasileiro aumentou mais de 10 anos (passando de mais de 62 anos, para quase 74 anos). Esse aumento se deve, dentre inúmeros outros fatores, à alteração das condições de saúde, com a ampliação do acesso aos serviços públicos de saúde, melhoria nas tecnologias de tratamentos de saúde e também da ampliação da rede de atendimento à família, principalmente para os mais pobres.

De toda sorte, remanescem os desafios de implementação de programas de qualidade com vistas à meIhoria dos serviços de saúde pública, inegavelmente deficiente, no Brasil. Em muitas localidades, os serviços de saúde são precários, o que gera a necessidade de deslocamentos de parte dos usuários para outros centros (médios e grandes), onde há um meIhor atendimento ou especialização. Consequência do incremento dessa demanda, revela-se no congestionamento da rede, em vista também do despreparo logístico e humano a penalizar justamente a maioria da população pobre, um atendimento de qualidade.

Contudo, não se pode negar reconhecimento aos 
Gráfico 3: Evolução do fator longevidade no IDH

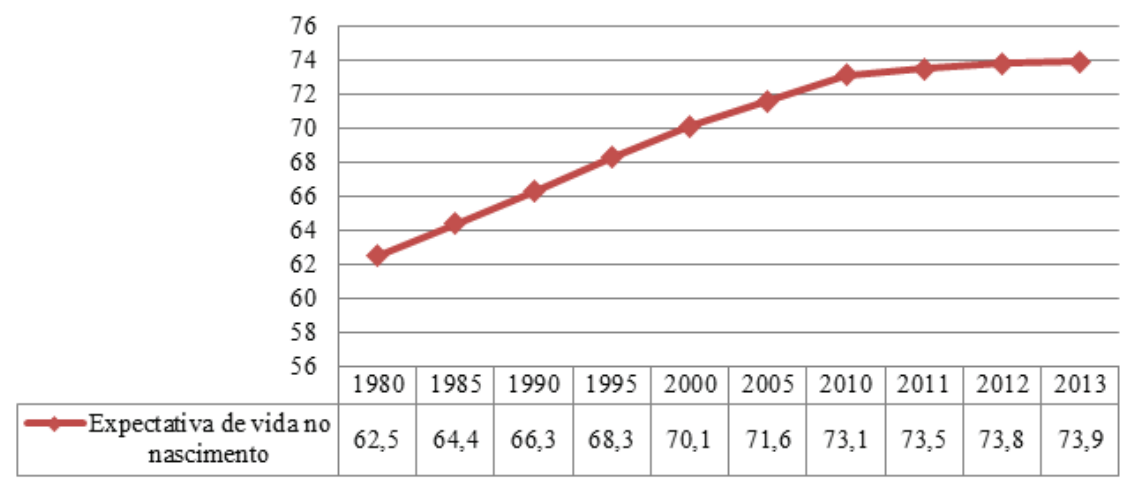

Fonte: Elaboração do autor; Fonte: IPEA, 2014.

avanços, embora insuficientes. O sistema de saúde brasileiro passou, desde a Constituição de 1988, por profundas transformações. Com a universalização, descentralização e ampliação da participação da sociedade nas decisões relacionadas às políticas de saúde, tornou-se um eixo temático da própria seguridade social. Embora patrono de um acesso precarizado, especialmente quanto às especialidades, o atendimento básico de saúde às famílias é amplo e possibilita que muitos problemas simples sejam tratados nas proximidades das residências dos cidadãos mais pobres. ${ }^{7}$

A correlação entre a exigência das condicionalidades saúde e educação e a evolução das duas variáveis, longevidade e educação, que compõem o IDH, repercutem na ampliação das possibilidades dos beneficiários do PBF em relação aos próprios instrumentos que promovem o desenvolvimento, garantindo verdadeira inserção social às camadas mais pobres da população brasileira.

7 Segundo dados do MDS no primeiro trimestre de 2015, das mais de 14 milhões de famílias beneficiadas pelo PBF, mais de $12 \mathrm{mi}$ Ihões foram atendidas pela rede de atendimentos do SUS, o que representa o acesso de 73,9\% dos beneficiários aos serviços de saúde. Desses acompanhamentos, mais de 5,5 milhões foram crianças, das quais 5,4 milhões (cerca de $99,2 \%$ do total) estavam com a vacinação em dia. Outros 234.286 atendimentos foram para mulheres gestantes, das quais $92 \%$ estavam com o pré-natal em dia. Os demais atendimentos corresponderam a outros serviços de saúde prestados às famílias beneficiárias do programa nas Unidades Básicas de Saúde. Há nas informações trazidas uma aderência ao objetivo do PBF de inserção social com a promoção da cidadania dos mais pobres.
3.2 Repercussões econômicas do Programa Bolsa Família: impactos do PBF na variável renda do IDH e no acesso ao trabalho

O incentivo às demandas de saúde, educação e serviços públicos básicos, promovido pela exigência das condicionalidades do PBF, deve ser fomentado ainda como aspecto da realização universal do mínimo existencial.

Na concepção dos direitos sociais, além das implicações relativas à educação e à saúde, há incremento econômico em razão do acesso à renda e ao trabalho. Dessa forma, as condicionalidades do PBF, na medida em que contribuem para o desenvolvimento econômico, refletem também um reconhecimento do valor social do trabalho - fundamento da República -, aqui entendido como o invólucro constitucional da proteção social e do próprio acesso ao trabalho, como elementos nucleares da cidadania das pessoas que tem capacidade de viver do seu próprio trabalhado.

A essa evidência, as ações do Programa Bolsa família devem refletir a ideia de conformação constitucional das políticas sociais brasileiras ao trabalho enquanto principal mecanismo produtivo, capaz de verdadeira inserção social no processo de desenvolvimento. Além dessas repercussões, pode-se afirmar que o efeito econômico promovido pelo PBF é: quanto ao direcionamento do gasto social, os valores são destinados para as mais de 14 milhões de famílias, as quais representam o beneficiamento de cerca de 50 milhões de pessoas. 
Em relação à magnitude do gasto social, os investimentos do PBF giram em torno de 0,5\% (cinco décimos por cento) do PIB per capita, ou seja, algo em torno de 27 milhões de reais, os quais são fruto do orçamento da União, composto pela receita de impostos e contribuições fiscais, os quais devem ser aplicados na realização dos diversos serviços públicos a cargo do Estado.

Analisando o retorno econômico-financeiro do programa, o IPEA apresenta o efeito econômico multiplicador do seu investimento, conforme se pode visualizar no Gráfico 4.

Segundo o levantamento apresentado no gráfico, os gastos com o PBF representaram, em 2014, 0,5\% (cinco décimos percentuais) do PIB brasileiro; mas cada $\mathrm{R} \$ 1,00$ (um real) gasto com o programa promoveu o retorno econômico de $\mathrm{R} \$ 1,78$ (um real e setenta e oito centavos).

A distribuição da renda fomenta a inserção socioeconômica e minimiza o problema da exclusão social, permitindo o acesso ao mercado de consumo, garantindo a inclusão e o respectivo retorno econômico aos mais pobres. Na mesma esteira, segundo dados do levantamento, a cada $\mathrm{R} \$ 1,00$ (um real) investido no Bolsa Família, o retorno econômico no mercado de consumo foi de $\mathrm{R} \$ \mathbf{2 , 4 0}$ (dois reais e quarenta centavos), o que expressa claramente a movimentação do mercado (NERI et al., 2013, p. 201-202) e a circulação dos recursos financeiros, especialmente nas regiões mais afetadas pela pobreza.
Por outro lado, a reflexão acerca da "solidariedade" na implementação do programa apresenta-se como complementar ao valor social do trabalho, nada obstante seja inconveniente tomar em consideração a eficiência das políticas assistenciais apenas pelos seus ganhos econômicos. Desta forma, a solidariedade reflete, como objetivo da república, a determinação ética para a assunção do compromisso social e jurídico para a realização do desenvolvimento que leve em consideração todas as pessoas, especialmente, as mais pobres.

Isto porque grande parcela da população brasileira, beneficiária dos programas sociais, não tem condições de comprar bens com o seu próprio ganho decorrente do salário/rendimento; e por essa razão a transferência de renda, fruto do Bolsa Família, desempenha relevante papel. É nesta esteira que o Bolsa Família repercute também na perspectiva renda, que compõe também o IDH.

Consoante informações do IBGE, consolidadas na Síntese de Indicadores Sociais (que analisa os dados socioeconômicos da população brasileira) do ano de 2013, os recursos econômicos oriundos do trabalho são a principal fonte de renda das famílias brasileiras, muito embora, nos últimos 10 anos (entre 2004 e 2013), conforme mostrado no Gráfico 5, tenha havido ampliação das fontes que compõem a renda do brasileiro.

À vista do infográfico, o trabalho continua sendo o principal componente da renda dos brasileiros, independentemente da faixa de renda familiar consi-

Gráfico 4: Repercussão Econômica do PBF

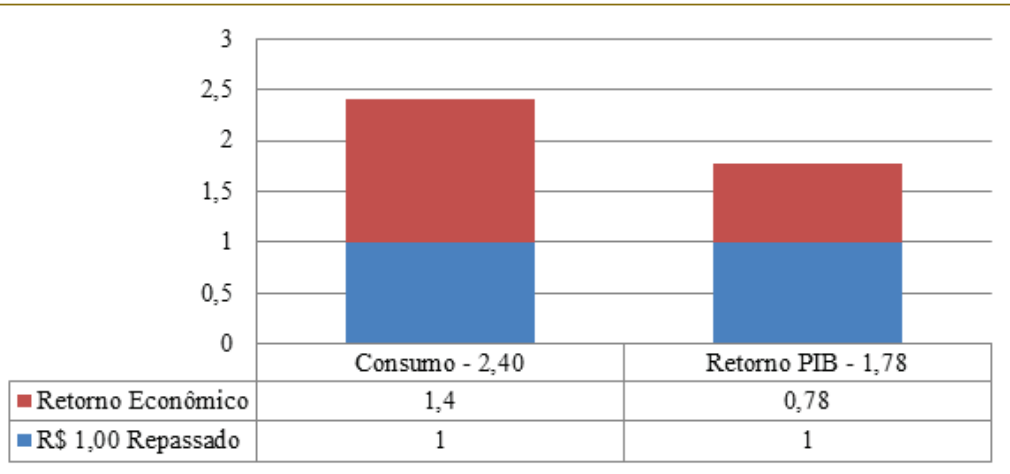

Fonte: Elaboração do autor; IPEA, 2013 
Gráfico 5: Distribuição do percentual dos rendimentos, por fonte dos rendimentos, total e arranjos familiares com até 1/4 e de mais de 1/4 até 1/2 salário mínimo de rendimento mensal familiar per capita no Brasil, em 2004 e 2013

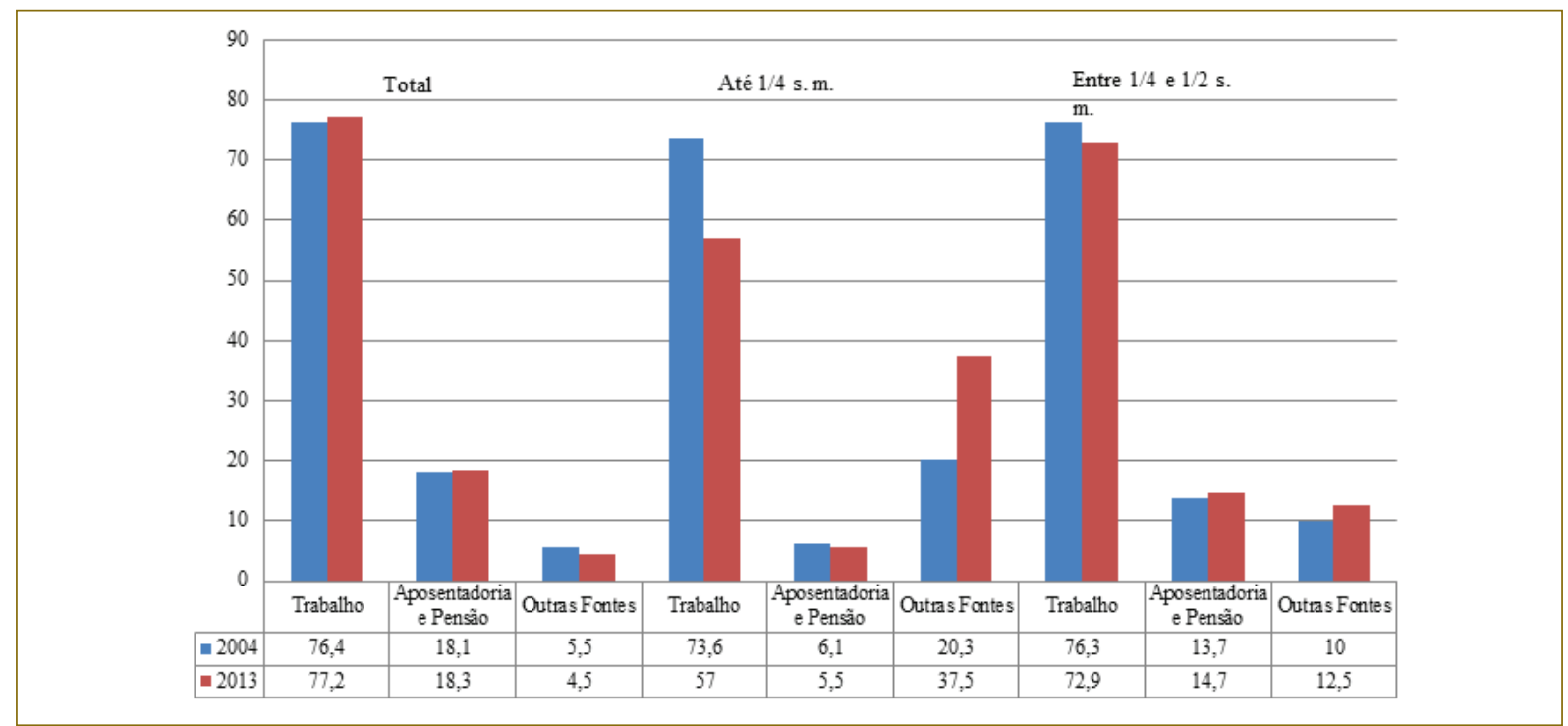

Fonte: IBGE, 2014.

derada. Rendimentos provenientes de aposentadorias, pensões, além do recebimento de benefícios sociais atuam de maneira complementar ao rendimento proveniente do trabalho, no sentido de garantir a ampliação do acesso à renda e de promover redução de desigualdades e atuar na concentração das riquezas.

Do total de brasileiros, os rendimentos do trabalho correspondem a $77,2 \%$ (setenta e sete inteiros e dois décimos por cento), em 2013, diante dos 76,4\% (setenta e seis inteiros e quatro décimos por cento), em 2004. A alteração no período considerado não foi tão grande, na totalidade das famílias pesquisadas, mas nas faixas de renda de até um quarto do salário mínimo e entre um quarto e metade de salário mínimo, a participação dos rendimentos do trabalho na composição da renda familiar sofreu um leve declive (de 73,6\% para $57 \%$, nas famílias com renda até um quarto do salário mínimo e de $76,3 \%$ para $72,9 \%$ nas famílias com renda entre um quarto e metade salário mínimo). Contudo, a involução da participação do trabalho na renda dos mais pobres não pode, numa visualização superficial, ser considerado um retrocesso.

A ampliação dos benefícios da assistência social, especialmente para aquelas famílias que antes não tinham outras possibilidades de acesso à renda, pro- move um alívio das mazelas decorrentes da pobreza. Com o fortalecimento da rede de proteção assistencial, elas passam a ter acesso a outras formas de renda que servem, na realidade, de complemento ao rendimento do trabalho.

As fontes de renda decorrentes de benefícios sociais e aposentadorias foram as responsáveis por promover a saída de milhares de famílias do grupo que recebe até um quarto de salário mínimo (rendimentos que correspondiam, em 2004 e 2013, respectivamente, a $6,1 \%$ e 5,5\%) para o grupo que recebe entre um quarto e metade do salário mínimo. 0 trabalho é o fator que retira as famílias deste último grupo para o grupo que recebe mais de um quarto de salário mínimo, uma vez que estas famílias não podem mais ser beneficiárias de muitos dos benefícios assistenciais.

A inclusão dos mais pobres, por meio, especialmente, dos benefícios decorrentes do Bolsa Família, promoveu a ampliação do acesso à renda. Ainda, nas colunas que tratam das "outras fontes" de renda, em especial entre as famílias mais pobres, com rendimento médio até um quarto do salário mínimo, eram responsáveis por 20,3\% (vinte inteiros e três décimos por cento), em 2004, passando, em 2013 para 37,5\% (trinta e sete inteiros e cinco décimos por cento). Como essas famílias não têm rendimentos provenientes de fontes 
como alugueis ou aplicações financeiras, esses outros rendimentos são atribuídos aos benefícios assistenciais, que tem possibilitado um patamar de consumo e de inserção econômica antes inexistente.

O MDS afirma que em 12 anos de existência do Programa Bolsa Família, mais de 3 milhões de famílias deixaram voluntariamente de ser beneficiárias por terem melhorado de renda (BRASIL, 2015d). Muitos são os fatores que impulsionam a ampliação da inserção socioeconômica dos mais pobres, dentre eles a "[...] retomada do crescimento econômico, o aumento da renda real, a redução do desemprego, a política da valorização do salário mínimo e a política de incentivo à formalização, como, por exemplo, a criação do Simples Nacional (IBGE, 2013)".

Muito embora a crise determine medidas de arrocho e ajustes que promovem um respiro às contas públicas, fazendo com que muitas daquelas conquistas das últimas décadas atualmente estejam estagnadas, o achatamento do poder de compra, a redução da capacidade de promoção do crescimento econômico pelo trabalho, o retrocesso social e a perda de direitos não podem ser consideradas situações normais. Ao contrário, devem ser adotadas medidas claramente alicerçadas no valor solidariedade, capazes de promover a superação da economicidade que pauta a regulação dos mercados, retirando a economia do confinamento da busca cega pela lucratividade, de modo “[...] a repensar valores e práticas que incluam a criatividade em favor dos grupos sociais (SILVA, 2014, p. 28)".

\section{Programa Bolsa Família x trabalho: repercussão socioeconômica das ações assistenciais na demanda por trabalho}

O trabalho, nesse contexto de transformações econômicas, permanece protagonista na tarefa de promover emancipação social, mesmo em face da crise econômica. A economia do trabalho passa a servir como instrumento de mediação e de equacionamento dos problemas sociais. A valorização do trabalho (e não o seu encolhimento) deve ser responsável pela geração de empregos capazes de promover uma reelaboração das esferas sociais e econômicas.
Em reforço argumentativo, o Tratado de Amsterdã, em seu artigo 109, N, dispõe que os Estados Membros e a sociedade devem estabelecer estratégias para o fortalecimento do trabalho, em especial do emprego, com a promoção de qualificação e formação de mão-de-obra.

Assim, a determinação constitucional do valor social do trabalho como fundamento da República e do primado do trabalho como fundamento da Seguridade, portanto, da assistência social, deve ser estabelecida como "[...] o início de uma democratização real" (REGO, 2013) da própria economia. Nesse contexto, o Estado é responsável por alterar o panorama social, já que protagonista de ações que promovem mudança macroeconômica no sentido do reconhecimento da pessoa humana como destinatário principal da ordem econômica.

A assistência social deve desempenhar o papel de instrumento garantidor da emancipação e da dignificação, com a ampliação do fator trabalho como pilar para a efetivação da vontade constitucional, o que reforça o argumento da solidariedade na atuação estatal. O que se formula como hipótese central à assistência social, com fundamento no valor social do trabalho, é que a renda monetária alcançada pelas famílias alcançadas pelo PBF deve possibilitar a criação e a ampliação das possibilidades laborais dos sujeitos sociais, garantindo-se-lhes desenvolvimento e autonomia.

Como resposta à crise, em vez da redução de direitos e limitação de investimentos sociais, deve ser elaborado um conjunto de ações de alicerce teórico fundado na solidariedade, com repercussões práticas, no sentido de concretizar a inclusão do valor social do trabalho nas ações da assistência social. É evidente, contudo, que para alcançar esse patamar de inserção laboral, muito ainda deve ser repensado em torno da implementação do Bolsa Família.

Especificamente, quanto à relação entre o Bolsa Família e a oferta de trabalho, a pesquisa da segunda rodada de Avaliação do Impacto do Bolsa Família (AIBFII), disponibilizada pelo MDS, mostrou que o programa não afeta a participação dos beneficiários no mercado laboral, seja em termos de ocupação, procura de emprego ou extensão da jornada de trabalho. 
A AIBFII foi realizada com 11.433 famílias, beneficiárias ou não do programa, em 2009. As informações apresentadas demonstram que a busca e a inserção laboral são preocupações para o público alvo do PBF. Segundo Jannuzzi e Pinto (2013), analisando as informações consolidadas do AIBFII, os chefes de famílias beneficiárias (entre 30 a 55 anos) apresentam níveis de atividade, ocupação e jornada muito semelhantes aos de chefes de nível socioeconômico equivalente e não beneficiários.

Nessa perspectiva de análise (MDS, 2015, p. 15), não restou comprovado impacto negativo sobre a força de trabalho em razão do recebimento do Bolsa Família, especialmente quanto aos homens. No que se refere à força de trabalho feminino, o recebimento do Bolsa Família atuou de modo inverso, de modo a estimular a inserção laboral, permitindo que houvesse aumento na busca por trabalho entre 5\% e 7\%.

No Nordeste, esse índice é ainda mais significativo: ampliou-se entre 9\% (nove por cento) e 11\% (onze por cento) o número de mulheres à procura de exercer algum tipo de atividade. Segundo o relatório, uma interpretação possível "é [a de] que o recebimento do Bolsa Família torna possível para as mulheres procurar melhores empregos do que elas encontrariam se não recebessem esses benefícios". ${ }^{8}$ Sugere-se, assim, que as mulheres que recebem o Bolsa Família teriam condições de se colocar melhor no mercado laboral, ampliando possibilidades de inserção econômica, que apenas é possível em razão do recebimento da renda oriunda do programa.

Principalmente no caso das mulheres, como devem encaminhar seus filhos à escola, e por não precisarem ficar em casa, elas acabam dispondo de mais tempo para se dedicar a uma atividade remunerada. Assim, o "PBF não causa um grande 'desencorajamento' para o trabalho (TEIXEIRA, 2010, p. 9)”. ${ }^{9}$

Teixeira (2010, p. 7) observa que a ampliação da probabilidade de quem recebe o benefício assistencial estar ocupado é maior (1,7\% a mais para homens e

8 Tradução do autor. No original: "[...] is that receipt of Bolsa Familia makes it possible for women to search for better jobs than would be the case if they did not receive these transfers."

9 Tradução do autor. No original: "[...] PBF does not cause a large work 'discouragement'”.
2,5\% para mulheres), do que entre pessoas da mesma faixa de renda que não participam do programa. Isto decorre principalmente da ligação do programa com a condicionalidade educação, em razão da qual as crianças devem frequentar a escola.

Rego e Pinzani (2014, p. 95), em seu destacado trabalho de pesquisa, entrevistaram mais de 150 (cento e cinquenta) mulheres beneficiárias do Bolsa Família, principalmente, no nordeste brasileiro, e identificaram, em seu discurso, que "[...] embora um número importante entre elas se queixasse do valor baixo do auxílio (muitas o definiram como 'uma ajuda')", quase todas afirmaram que preferiam um trabalho regular ou que seus maridos trabalhassem.

Essa afirmativa de preferir o trabalho ao auxilio pecuniário do Bolsa Família é recorrente nas inúmeras entrevistas realizadas por Rego e Pinzani. Em uma delas, o desejo de trabalhar é retratado de modo claro: "Olha, o que nós queremos, a mudança, é de uma vida melhor, eu queria mesmo ganhar é suado meu salário, que tivesse que trabalhar, toda mãe quer isso para seus filhos, sua família, sua casa (REGO; PINZANI, 2014, p. 141)". ${ }^{10}$

Rego e Pizani (2014, p. 95) afirmam, ainda, que dentre as 150 (cento e cinquenta) entrevistadas “[...] somente duas afirmaram ter deixado de trabalhar para viver da bolsa. Ambas trabalhavam como empregadas domésticas para famílias de classe média recebendo um 'salário' de R\$ 150,00 e R\$ 200,00 (para trabalhar semanalmente 6,5 e 6 dias respectivamente)". O fato, segundo as autoras, se explica pelo valor relativamente baixo da ajuda financeira, que não é suficiente para garantir todas as necessidades do núcleo familiar, levando à necessidade de uma complementação de renda com outras atividades (a maioria delas precária, temporária e de remuneração ínfima).

Muitas beneficiárias veem a dependência do programa como uma condição de vergonha, apesar de reconhecerem que a assistência proporcionada possibilita uma perspectiva de futuro, principalmente para os seus fiIhos - quase a totalidade, na escola, em razão, inclusi-

10 Entrevista realizada com Dona Inês - 30 anos, separada, mãe de dois filhos, de 12 e 8 anos, ensino médio completo, na cidade de Demerval Lobão, no Piauí. 
ve, da condicionalidade educação. Como afirmam, há, "[...] nas mulheres entrevistadas, um aumento de autoestima, que aponta para a geração de níveis mínimos de autonomização na gestão da vida em geral (REGO; PINZANI, 2014, p. 122)", mas principalmente pela possibilidade de serem as definidoras das opções (econômicas e, muitas vezes, morais) de suas famílias.

O Bolsa Família não deve representar apenas um acréscimo na renda de pessoas mais pobres, mas deve estabelecer, nos termos da Associação Internacional da Seguridade Social, "[...] mudanças culturais com relação à participação no mercado do trabalho e na utilização dos serviços de saúde e de assistência escolar (ISSA, 2010, p. 4)", de modo a funcionar como instrumento de combate à crise econômica.

Até 2014, segundo dados do IBGE, o Bolsa Família permitiu que cerca de 1,7 milhão ultrapassassem a linha de pobreza e deixassem de receber a transferência de rendimentos condicionada, por não precisarem mais do auxílio governamental. Ainda, segundo dados do Censo 2010, do IBGE, 75,4\% dos beneficiários do Bolsa Família mantiveram normalmente suas atividades laborais, fato que demonstra que o benefício não estimula o afastamento das atividades laborativas (CAMPELLO, NERI, 2013).

A grande dificuldade é a ausência de postos de emprego, cujo fechamento decorre da crise econômica e tem levado cada vez mais pessoas para a informalidade e para condições de extrema exploração. Nessa perspectiva, o Estado deve atuar possibilitando que os beneficiários do Bolsa Família, que tem acesso à renda assistencial, possam aliar ao reforço da renda familiar. Como mencionam Rego e Pinzani (2014, p. 182), no caso das mulheres beneficiárias do Bolsa Família,

[...] a grande maioria jamais teve um emprego, pelo fato de casar e ter filhos ainda muito jovens. No máximo, elas e os maridos conseguem alguns "bicos", trabalhos temporários duros e mal remunerados (por exemplo: 8 horas de lavoura na roça por $R \$ 10,00$, como relatado por várias mulheres em Inhapi), e vivem em incerteza continua sobre o futuro.

Deve-se-lhes permitir exercer outras atividades laborais, economicamente sustentáveis. Essas atividades são capazes de conduzir esses beneficiários da assistência social a um padrão de estabilidade social que os retire da condição de pobreza, como é o caso, por exemplo, dos "350 mil microempreendedores individuais brasileiros, oriundos do Bolsa Família, que hoje incrementam a economia formal do país (MOREIRA, 2013)”.

A rede de inserção produtiva, que promove emancipação e elevação do patamar socioeconômico dos seus participantes deve estar apta a proporcionar a esses sujeitos novas perspectivas de integração ao mercado de trabalho.

\section{Conclusão}

Políticas sociais como o Programa Bolsa Família devem ser capazes de agregar mecanismos que auxiliem as pessoas a integrar-se à economia formal e aos meios de promoção de inserção social, cujo vínculo apenas é possível através do trabalho.

Medidas voltadas à inserção laboral devem ser efetivadas no intuito de garantir a conformação das políticas assistenciais ao valor social do trabalho. Nesse sentido, a busca pelo emprego deve ser incentivada, bem como a ampliação da rede de absorção do trabalho informal pelo mercado formal, de modo a se viabilizar a efetivação de direitos sociais mínimos, com o fortalecimento e a implementação da regulamentação do mercado de trabalho.

Incentivos para o aumento da proteção ao trabalhador oriundo dos programas sociais de assistência e a superação da crise econômica enfrentada revelam-se mecanismo de saída para o desenvolvimento e efetivação da justiça social. Fica evidente a importância do vínculo dos programas assistenciais com outros componentes do sistema de proteção social na ampliação das possibilidades socioeconômica para os mais pobres.

As ações da assistência social atacam as vulnerabilidades sociais e econômicas e permitem o empoderamento a partir do acesso à renda mínima e aos direitos sociais sedimentados no cumprimento das condicionalidades do programa, o que resulta em aprimoramento e evolução do próprio IDH.

É importante que ações solidárias voltadas para o 
trabalho sejam favorecidas como meio de impedir rebatimento dos efeitos da crise econômica, especialmente em relação aos mais pobres. Para que os resultados econômicos no IDH possam continuar positivos, os sujeitos sociais devem estar habilitados à ocupação de postos de trabalho, com acesso à educação e à saúde de qualidade, permitindo-se-lhes efetiva participação nos processos sociais e dignificação nas lutas por transformações duradouras.

A superação da dificuldade recente que se avoluma com a crise, referida nos índices de desemprego deve ser o foco principal das ações Estatais no sentido da promoção do desenvolvimento e do bem-estar. Isso porque, a diminuição importante de postos de emprego tem excluído cada vez mais pessoas, relegando-as à informalidade, ao tempo em que promovem o indesejável retorno a condição de extrema pobreza. Nisto, pois, consiste o desafio da rede de inserção produtiva: promover a emancipação e a elevação do patamar socioeconômico dos beneficiários do Programa Bolsa Família e proporcionar a esses sujeitos novas perspectivas de integração ao mercado de trabalho. (MDS, 2015)

HIIIIIIIIIIIIIIIIIIIIIIIIIIIIIIIIII

\section{Referências}

BRASIL. (2015). Dados do acompanhamento da condicionalidade educação do Bolsa Família - junho/ julho de 2015. Acesso em 31 de out. de 2015, disponível em Ministério do Desenvolvimento Social e Combate à Fome: http://mds.gov.br/area-de-imprensa/dados

Brasil. (2015). Dados do Bolsa Família. Brasília: Ministério do Desenvolvimento Social e Combate à Fome. Acesso em 31 de out. de 2015, disponível em http://mds.gov.br/area-de-imprensa/dados

Brasil. (9 de jun. de 2015). Orçamento garante aumento de recursos para Bolsa Família. Fonte: Portal Brasil: http://www.brasil.gov.br/cidadania-e-justica/2015/06/orcamento-garante-aumento-de-recursos-para-bolsa-familia

Campelo, T., \& Marcelo , C. N. (2013). Programa Bolsa Família: uma década de inclusção e cidadania. Brasília: IPEA.

Coutinho, A. L. (2003). Servidor Público: reforma administrativa, estabilidade, empregado público, direito adquirido. Curitiba: Juruá.

Fagnani, E. (1997). Política social e pactos conservadores no Brasil: 1964/1992. Cadernos FUNDAP, 21, pp. 59-102.

IBGE. (2013). Síntese de indicadores socaiis: uma análise das condições de vida da população brasileira. Estudos e pesquisas, informação demográfica e socioeconômica.

IBGE. (2014). Síntese de indicadores sociais: uma análise das condições de vida da população brasileira. Estudos e pesquisas, informação demográfica e socioeconômica.

IPEA. (1 de out. de 2013). Comunicados do IPEA: duas décadas de desigualdade e pobreza no Brasil medidas pela PNAD/IBGE.

ISSA. (2010). A Dynamic social security for the Americas: social cohesion and institucional diversity developments and trends. Acesso em 8 de jun. de 2015, disponível em www.issa.int

MDS. (2015). Segunda Rodada (AIBF II). Avaliação de impacto do Bolsa Família.

Moreira, R. d. (2013). Empreendedorismo e inclusão produtiva: uma anállilse de perfil do microempreendendor individual beneficiário do programa bolsa família. Radar: tecnologia, produção e comércio exterior(25). 
Neri, M. C., Vaz, F. M., \& Souza, P. G. (2013). Efeitos macroeconômicos do programa bolsa família: uma análise comparativa das tranferências sociais. Em T. Campelo, \& M. C. Neri, Bolsa Família: uma década de inclusão e cidadani. Brasília: IPEA.

Quirino, M. G. (2009). Crise ambiental: Recuros hídricos e o desenvolvimento sustentável na Paraíba. João Pessoa: Mestrado em Direito do Programa de Pós-Graduação em Ciências Jurídicas.

Rego, W. L. (11 de jun. de 2013). Bolsa Família enfraquece o coronelismo e rompe a cultura da resignação, diz socióloga. (E. d. Lucena, Entrevistador) São Paulo: Folha de São Paulo. Acesso em 2 de jun. de 2015, disponível em http://www1.folha. uol.com.br/poder/2013/06/1293113-bolsa-familia-enfraquece-o-coronelismo-e-rompe-cultura-da-resignacao-diz-sociologa.shtml

Rego, W. L., \& Pinzani, A. (2014). Vozes do Bolsa Família: autonomia, dinheiro e cidadania. São Paulo: UNESP.

Silva, E. P. (2014). Reinvenção da cidade, produção fílmica e visibilidade sociocultural. o uso do território na Roliúde Nordestina - Cabaceira-PB, 152. (P. d.-G. Sociais, Ed., \& UFRN, Compilador) Natal: UFRN.

Stone, D. (2002). Police Paradox: the art of the political decision makin. New York, London, USA: Norton and Company.

Teixeira, C. G. (2010). A heterogeneity analysis of the Bolsa Familia Programme effect on men and women's work supply. (I. P. Growth, Ed.) Working paper(61).

Data de submissão/Submission date: 25.08.2016.

Data de aceitação para publicação/Acceptance date: 04.05.2017. 